\title{
As mudanças nas formas de gestão escolar no contexto da nova gestão pública no Brasil e em Portugal
}

\section{Changes in the forms of school management in the context of new public management in Brazil and Portugal}

\author{
Regina Tereza Cestari de Oliveira*
}

\begin{abstract}
RESUMO
O artigo tem como objetivo analisar, no contexto de redefinição do papel do Estado, as mudanças nas formas de gestão escolar que foram sendo incorporadas na legislação educacional no Brasil e em Portugal, nas últimas décadas. São países com trajetórias distintas quanto à função do Estado na garantia do direito à educação, às políticas de democratização da educação e à institucionalização da gestão democrática nas escolas, no entanto são países que experimentaram longos períodos de regimes autoritários. A investigação apoia-se na literatura nacional e internacional sobre o tema e em fontes documentais, tomando-se como referência a Lei de Diretrizes e Bases da Educação Nacional (LDB) de 1996, no Brasil, e a Lei de Bases do Sistema Educativo (LBSE) de 1986, em Portugal. O pressuposto é que essas mudanças nos normativos legais provocam uma ruptura no princípio da gestão democrática instituído na Constituição da República Federativa do Brasil de 1988 e na Constituição da República Portuguesa de 1976, com a ascensão de um modelo de gestão escolar centrado na eficácia e na eficiência, com fundamento na Nova Gestão Pública.
\end{abstract}

Palavras-chave: Nova Gestão Pública. Gestão escolar. Gestão democrática.

* Universidade Católica Dom Bosco, Programa de Pós-Graduação em Educação. Campo Grande, Mato Grosso do Sul, Brasil. E-mail: reginacestari@hotmail.com. https://orcid.org/00000001-5500-7478. 


\begin{abstract}
The paper aims to analyze, in the context of redefinition of State's role, the changes in the forms of school management that have been incorporated in the educational legislation in Brazil and Portugal in the last decades. They are countries with different trajectories regarding the role of the State in guaranteeing the right to education, policies for the education democratization, and the democratic management institutionalization in schools. However, these countries have experienced long periods of authoritarian regimes. The research is supported by the national and international literatures on the subject and in documentary sources, taking as reference the Law of Guidelines and Bases of National Education (LDB) of 1996 in Brazil and the Basic Education System Law (LBSE) of 1986, in Portugal. The assumption is that these changes in legal norms cause a rupture in the principle of democratic management instituted in the Constitution of the Federative Republic of Brazil of 1988 and in the Constitution of the Portuguese Republic of 1976, with the rise of a school management model focused on effectiveness and efficiency, based on the New Public Management.
\end{abstract}

Keywords: New Public Management. School management. Democratic management.

\title{
Introdução
}

Este artigo apresenta resultados de pesquisa ${ }^{1}$ desenvolvida com o objetivo de analisar as mudanças nas formas de gestão escolar que foram sendo incorporadas na legislação educacional, nas últimas décadas, no contexto de redefinição do papel do Estado, no Brasil e em Portugal.

A discussão apoia-se na literatura nacional e internacional, ou seja, em autores que problematizam e analisam o tema em questão e no levantamento e análise documental. Para tanto, focalizou os marcos legais que vieram regular a gestão da educação nos dois países, tomando-se como referência a Lei de Diretrizes e Bases da Educação Nacional (LDBEN), de 20 de dezembro de 1996, no Brasil, que estabelece as diretrizes e bases da educação brasileira (BRASIL, 1996), e a Lei de Bases do Sistema Educativo (LBSE), de 14 de outubro de

1 Pesquisa com financiamento da Fundação de Apoio ao Desenvolvimento do Ensino, Ciência e Tecnologia do Estado de Mato Grosso do Sul (Fundect) e do Conselho Nacional de Desenvolvimento Científico e Tecnológico (CNPq). 
1986, em Portugal (1986), que estabelece o quadro geral do sistema educativo português (PORTUGAL, 1986).

Leva em consideração que são países com trajetórias distintas no que se refere à função do Estado na garantia do direito à educação, às políticas de democratização da educação, assim como à institucionalização da gestão democrática nas escolas. No entanto, como assinala Lima (2014, p. 1068), são países que experimentaram por longos períodos a vigência de regimes autoritários e, portanto, parece não ser possível encontrar um ideal político-educativo mais completo de significado democrático e com maior potência transformadora do que aquele que, "tendo sido assumido como utopia, reivindicação e palavra-de-ordem foi expresso na "categoria gestão democrática das escolas"” (LIMA, 2014, p. 1068).

A intenção, portanto, não é fazer uma análise comparada dessas mudanças na legislação educacional desses países, compreendendo, como expressa Roger Dale, em entrevista realizada por Luís Armando Gandim, que "você não pode comparar situações empíricas por uma série de razões históricas". Nesse sentido, o mais interessante e importante, comparativamente, ou o que se pode comparar e aprender, "são as razões que se dá para fazer algo, o que envolve olhar para os casos em diferentes graus de abstração. Há uma certa cadeia de abstração" (DALE; GANDIM, 2014, p. 11).

Tal intento parte da análise de Afonso (2001) ao se referir à nova conjuntura a partir de meados dos anos 1980 e dos anos 1990 e apresentar o entendimento de que,

[...] apesar de ser necessário problematizar os efeitos (não lineares e contraditórios) da globalização e discutir a sua própria configuração como nova e poderosa ideologia, a análise sociológica das políticas educativas continua a não poder abrir mão da referência ao papel e à natureza do estado nacional e às suas relações com as classes sociais, e a não dispensar, portanto, o entendimento das especificidades (culturais, sociais, políticas, econômicas e educacionais) que estão impregnadas da (e na) história de uma dada formação social (AFONSO, 2001, p. 36).

De tal modo, busca-se, inicialmente, situar o Estado enquanto sujeito histórico no contexto de aceleração da globalização econômica e de redefinição do seu papel, tomando-o, genericamente, como instituição política. 


\section{O Neoliberalismo e a nova gestão pública}

Na fase de expansão capitalista após a Segunda Guerra Mundial (19391945), a reestruturação das formas de Estado e das relações internacionais buscava impedir as ameaças ao poder capitalista e o Estado-providência passou a ser a fórmula encontrada por muitos países para a gestão das contradições que foram se acirrando, por um lado, devido à necessidade de o Estado intervir na economia e, por outro, de ter que criar condições para atender às crescentes expectativas e às necessidades sociais, sendo muitas delas decorrentes do direito de cidadania (proteção social, saúde, educação, entre outros).

O período de acumulação capitalista, denominado por Harvey (2013, p. 119) de "fordista/keynesiano", fundamenta-se em um conjunto de práticas de controle do trabalho, tecnologias, hábitos de consumo e configurações do poder político-econômico, e se desenvolveu entre o pós-Segunda Guerra (1945) e a crise do petróleo (1973). A partir desta crise que, segundo Mészáros (2009, p. 65-67), "não se reduz simplesmente a uma crise política, mas trata-se da crise estrutural geral das instituições capitalistas de controle social na sua totalidade", iniciou um período de "rápida mudança, de fluidez e de incerteza" e provocou, na sequência, a combinação de estagnação econômica e preços em rápido crescimento - "estagflação" (HOBSBAWM, 2008, p. 399).

Em resposta à sua própria crise, iniciou-se um processo de reorganização do capital e do seu sistema ideológico e político de dominação, ou seja, o neoliberalismo, com a privatização do Estado, a desregulamentação dos direitos do trabalho e a desmontagem do setor produtivo estatal (ANTUNES, 1999).

O processo de neoliberalização, de acordo com Harvey (2012), abrange muita "destruição criativa", tanto dos antigos poderes e estruturas institucionais (chegando mesmo a abalar as formas tradicionais de soberania do Estado), como das divisões do trabalho, das relações sociais, da promoção do bem-estar social, das combinações de tecnologias, dos modos de vida e de pensamento, das atividades reprodutivas, das formas de ligação à terra e dos hábitos do coração. $\mathrm{O}$ autor acentua que o "bem social é maximizado se se maximizam o alcance e a frequência das transações de mercado, procurando enquadrar todas as ações humanas no domínio do mercado" (HARVEY, 2012, p. 12).

A crítica mais acentuada ao modelo do Estado-providência ou Estado de bem-estar social e à intervenção pública na economia e distribuição social provém dos setores liberais e conservadores que integram a chamada nova direita, isto é, "uma coligação política, resultante de interesses e valores contraditórios, 
que irá marcar a agenda ao longo dos anos oitenta em muitos países" (AFONSO, 1998, p. 139).

A despeito de o neoliberalismo propagar o recuo do papel do Estado, é preciso reconhecer que, no contexto da globalização econômica, os Estados nacionais desempenham um papel ativo, aliados a outros agentes da globalização, especialmente outros Estados, na execução de uma agenda internacional do capital. Assim, o Estado é ainda uma característica proeminente no cenário das políticas educacionais, e, apesar de não ser mais um "Estado nacional", nem um "Estado executivo eficiente", continua sendo o coordenador em último recurso, assim como o "lugar para onde se dirigir quando os outros agentes de governança falham", da mesma maneira que, o único meio quando os problemas centrais parecem não estar resolvidos (DALE, 2010, p. 1106).

E nesse contexto, ao mesmo tempo, é crucial para o Estado o desenvolvimento da forma política do neoliberalismo, geralmente chamada de Nova Gestão Pública, destacando como uma das suas características-chave "o fato de, em conformidade com o neoliberalismo, não funcionar contra o Estado, mas através dele" (DALE, 2010, p. 1104, grifos do autor). Em outros termos, "A maior mudança na forma do Estado é sem dúvida sua reformulação em uma forma mais parecida com o mercado, mais parecida com o mundo dos negócios, que nós chamamos mais amplamente de "nova gestão pública"' (DALE; GANDIM, 2014, p. 7).

Essa fase compreende uma agenda com estratégias políticas e econômicas voltadas à revalorização do mercado de que fazem parte: a reformulação das relações do Estado com o setor privado, a adoção de novos modelos de gestão pública centrados na eficácia e na eficiência, assim como a redefinição dos direitos sociais (AFONSO, 1998).

\section{Redefinição do papel do Estado no Brasil e em Portugal}

No caso brasileiro, vale recordar que, com o golpe civil-militar em 1964, o país viveu um período de ditadura que se estendeu até o início de 1985. Os anos 1980 foram marcados por um processo de abertura política, em que segmentos representativos da sociedade civil lutavam por direitos sociais, no contexto de redemocratização da sociedade brasileira e que se desencadeou no processo Constituinte de 1987-1988. Esse processo de luta de segmentos sociais organizados resultou em conquistas importantes na Constituição Federal de 1988, como no Art. 6. ${ }^{\circ}$, a declaração de direitos sociais (BRASIL, 1988). 
Nesse período, à medida que no Brasil se criavam mecanismos político-democráticos de regulação da dinâmica capitalista, em âmbito mundial esses mecanismos perdiam vigência e tendiam a ser substituídos pela ideologia neoliberal, "pela desregulamentação, pela flexibilização e pela privatização elementos inerentes à mundialização (globalização) operada, sob o comando do grande capital" (NETTO, 1999, p. 77, grifos do autor).

Como analisa Cury (2013), no momento em que a Constituição da República de 1988 foi promulgada, os intensos ventos provenientes da Inglaterra, dos Estados Unidos, da Austrália e do Chile sopravam em direção contrária aos direitos sociais tão claramente proclamados, sendo que contavam com o apoio de parte da elite dirigente do país.

Na mesma direção, Peroni (2013) assinala que a construção da democracia no país viveu um processo de abertura pactuado com as forças da ditadura, e acentua que, nesse período, já estavam em curso em âmbito mundial as estratégias para superação da crise do capital, cujas propostas apresentavam-se em sentido contrário ao movimento de luta por direitos sociais, em um processo de diminuição de direitos conquistados.

Nesse contexto, o Plano Diretor da Reforma do Aparelho do Estado (Pdrae), elaborado em 1995, no primeiro mandato do Governo Fernando Henrique Cardoso (1995-1998), pelo então Ministério da Administração e da Reforma do Estado (Mare), na gestão de Luís Carlos Bresser Pereira, identificou o Estado como responsável pela crise econômica, argumentando que "[...] a causa da desaceleração econômica nos países desenvolvidos e dos graves desequilíbrios na América Latina e no leste europeu, era a crise do Estado que não soubera processar de forma adequada a sobrecarga de demandas a ele dirigidas [...]" (BRASIL, 1995, p. 10) e, portanto, deverá alterar sua dinâmica e funcionamento e buscar o parâmetro de qualidade no privado. Nesse sentido, propõe a substituição do padrão burocrático de gestão pública pela administração pública gerencial (BRASIL, 1995).

Ao definir estratégias de privatização, descentralização e publicização (público-não estatal), o Pdrae toma como um dos mecanismos de atuação a efetivação das parcerias entre o privado, especialmente o terceiro setor, e os sistemas públicos de ensino, estimuladas com subsídios públicos (PERONI; OLIVEIRA; FERNANDES, 2009).

Nessa conjuntura, o princípio da eficiência, presente no Pdrae, ganhou status constitucional com o Art. 37 da Emenda Constitucional (EC) n. ${ }^{\circ}$ 19, de 4 de junho de 1998, ao estabelecer que "A administração pública direta e indireta de qualquer dos Poderes da União, dos Estados, do Distrito Federal e dos Municípios obedecerá aos princípios de legalidade, impessoalidade, moralidade, publicidade e eficiência [...]" (BRASIL, 1998). Desse modo, "permitiu a fle- 
xibilização das relações entre a iniciativa privada e o poder público, a partir da inserção de práticas gerenciais advindas de modelos privatistas, considerados, nessa perspectiva, mais eficientes e ágeis" (ADRIÃO; BEZERRA, 2013, p. 264).

Assim, desde os anos de 1990, sob a égide da ordenação neoliberal, esse princípio vem se afirmando na administração pública e, também, na educação brasileira. Nesse sentido, afirma Frigotto (2011, p. 245), “[...] é dada ênfase aos processos de avaliação de resultados, balizados pelo produtivismo e à sua filosofia mercantil, em nome da qual os processos pedagógicos são desenvolvidos mediante a pedagogia das competências".

Justifica-se essa lógica "eficientista", segundo Oliveira (2015, p. 642), por critérios de justiça baseados no mérito individual, "que repousa sobre uma perspectiva homogênea e padronizada de avaliação para fundamentar uma distribuição diferenciada".

As práticas gerenciais manifestam-se, portanto, na responsabilização dos gestores escolares e dos professores pelos resultados da avaliação externa, na premiação pelo sucesso da escola, no estímulo às parcerias entre as escolas e os setores privados, que disputam recursos públicos, entre outros, como forma moderna de participar da melhoria da qualidade do ensino público, no sentido de contribuir para o aumento da eficácia e da eficiência da escola, que se traduz no empenho em se atingir o máximo de resultados com o mínimo de dispêndio.

Nessa perspectiva, as reformas dos anos de 1990 realizadas no Brasil, que se pautaram nos fundamentos da Nova Gestão Pública, com o argumento da racionalização da gestão pública, contribuíram para a diminuição da concepção de direito e da concepção de público, que nos anos de 1980 orientou o processo constituinte brasileiro (OLIVEIRA, 2015).

No que se refere a Portugal, segundo Afonso (2012), a partir de meados dos anos 1980 e dos anos 1990, alguns vetores da ideologia neoliberal começaram a ter algum impacto no país, porém, nas décadas seguintes, outros fatores foram permitindo que as mudanças no papel do Estado e as políticas governamentais fossem mais permeáveis à ideologia de mercado e suas diferentes formas de materialização.

Entre essas formas, Lima (2002) assinala que, embora recente no campo educativo, a obsessão pela eficácia, pela eficiência e pela qualidade consiste em um pensamento tipicamente tayloriano e que se encontra presente por diferentes formas na teoria da burocracia, na escola das relações humanas, nas perspectivas sistêmicas e contingenciais, entre outros. No entanto enfatiza que a novidade

[...] residirá, apenas, na insistência com que é referida no sector educacional, ganhando foros de inovação. A reedição de programas, de méto- 
dos e de técnicas, que tem feito carreira na administração das empresas, sobretudo a partir da década de sessenta, agora no contexto educativo, é mais um sinal a confirmar a adopção de um modo de racionalidade econômica (LIMA, 2002, p. 26).

Com intensidade crescente na primeira década do século XXI, em Portugal, o campo das políticas públicas vem sendo modelado por movimentos gerados no conjunto de tensões, disputas, derrotas e contradições, por exemplo, de "evasão do Estado à obrigação de garantir o direito social e humano das populações adultas à educação, enquanto amplia para patamares inéditos a oferta pública de educação e a população abrangida" (ANTUNES, 2013, p. 82-83).

Assim, considerando esse período particular do capitalismo, em que o lugar e a força dos Estados nacionais foram amplamente alterados (DALE, 2010), assim como o papel do Estado para com as políticas sociais, é que se busca discutir, na próxima seção, como a gestão democrática se traduz no arcabouço jurídico legal que regulamenta a educação, com destaque para as alterações nas formas de gestão escolar que foram sendo instituídas nos normativos legais dos países em questão.

\section{A gestão democrática na legislação educacional brasileira e portuguesa}

Vale lembrar que, no Brasil, no processo de luta pelo retorno à democracia, na década de 1980, o tema gestão democrática integrava a pauta dos educadores que reivindicavam, entre outros, mecanismos de participação - eleição de dirigentes escolares, instituição de conselhos escolares, elaboração de regimento e de projeto pedagógico de forma coletiva, exclusividade do financiamento da escola pública pelo poder público. "Buscava-se instalar mecanismos de gestão baseados na organização democrática dos diferentes setores que compunham a 'comunidade escolar'” (ADRIÃO, 2006, p. 57). Nos termos de Saviani (2013, p. 216), "[...] a gestão democrática expressava os anseios dos professores de participação nas decisões, em contraposição à sua exclusão levada a efeito pelo regime autoritário".

Após o período de ditadura civil-militar (1964-1985), a Constituição Federal de 1988 incorporou no Art. 205, entre os princípios pelos quais se deve pautar a educação brasileira (VI), a "gestão democrática do ensino público, na 
forma da lei" (BRASIL, 1988). Apesar de restringir a gestão democrática ao ensino público, os direitos sociais declarados e os princípios da educação nacional incorporados nessa Constituição, com a presença inédita da gestão democrática como um desses princípios, indicam avanços em termos de luta e de legislação.

Esse princípio constitucional fundamenta-se na noção de Estado Democrático de Direito, tal como expresso na mencionada Constituição, no seu Preâmbulo e no seu art. $1^{\circ}$, inclusive seu parágrafo único. Nesse sentido, "A Gestão democrática é um princípio do Estado nas políticas educacionais que espelha o próprio Estado Democrático de Direito e nele se espelha postulando a presença dos cidadãos no processo e no produto de políticas dos governos" (CURY, 2002, p. 172).

Compreende-se, conforme Peroni (2012), que a gestão democrática do ensino é um componente do projeto de construção da democratização da sociedade brasileira, sendo que os elementos que a integram, como a construção do projeto político-pedagógico, a participação em conselhos, a eleição para diretores, a autonomia administrativa e financeira, são processos pedagógicos de aprendizagem da democracia, tanto para a comunidade escolar quanto para a comunidade em geral, sendo que, após muitos anos de ditadura, a participação nas discussões e nas tomadas de decisão é um longo processo de construção.

A Lei de Diretrizes e Bases da Educação Nacional (LDBEN), Lei n. ${ }^{\circ}$ 9.394, de 20 de dezembro de 1996, reafirma os princípios do ensino definidos na Constituição Federal de 1988, atribuindo no Art. 3..$^{\circ}$ (Inciso VIII), "gestão democrática do ensino público, na forma desta Lei e da legislação dos sistemas de ensino" (BRASIL, 1996). Isso significa que, ao regulamentar o princípio da gestão democrática definido no Art. 14 da Constituição Federal de 1988, delegou aos sistemas de ensino a prerrogativa de sua construção e operacionalização.

Essa transferência de responsabilidade permitiu que as unidades subnacionais construíssem políticas de gestão de sistemas e de unidades escolares diversas até hoje. Por exemplo, encontram-se nos estados e municípios do país aqueles que instituíram instrumentos de democratização da educação (eleição de diretores, eleição de colegiados escolares, instituição de conselhos escolares, construção coletiva do projeto pedagógico da escola), até aqueles em que as decisões no âmbito escolar são somente emanadas dos sistemas de ensino, ou mesmo quando há projeto pedagógico, este é resultado, apenas, da tarefa exigida pela burocracia institucional (FERNANDES; SCAFF; OLIVEIRA, 2013).

Quanto ao processo de escolha para provimento do cargo de diretor escolar, pode-se mencionar, grosso modo, três modalidades: nomeação direta pelo poder executivo, concurso público e eleição pela comunidade escolar. Porém verifica-se a crescente modalidade que combina a aplicação de avaliação de competências básicas, mediante prova escrita aos candidatos, seguida de eleição. Apesar de 
não constituir nenhuma certeza em termos da democratização da escola, uma vez que é apenas uma das medidas necessárias, "a eleição é a única que tem virtude para contribuir para o avanço de tal democratização" (PARO, 2011, p. 47).

A gestão democrática apresenta-se, também, na Lei n. ${ }^{\circ}$ 10.172, de 2001, que aprovou o Plano Nacional de Educação (2001-2010) (BRASIL, 2001), considerando o Art. 87, § 1. ${ }^{\circ}$ da LDBEN e sancionada com nove vetos pelo presidente Fernando Henrique Cardoso (1999-2002), que incidiram sobre o aspecto financeiro (SAVIANI, 2014). Define como um dos objetivos e prioridades do Plano a democratização da gestão do ensino público, nos estabelecimentos oficiais, atendendo os princípios da participação dos profissionais da educação. Observa-se que a Meta 22 do Plano confirma as normas de gestão democrática do ensino público, em cada sistema de ensino com a participação da comunidade (BRASIL, 2001).

Esgotado o período de vigência do referido plano, e após a realização da Conferência Nacional de Educação (Conae), intitulada "Construindo um Sistema Nacional Articulado de Educação: Plano Nacional de Educação, suas Diretrizes e Estratégias de Ação", no período de 28 de março a $1 .^{\circ}$ de abril de 2010, precedida de Conferências Municipais, Estaduais e do Distrito Federal, o governo de Luiz Inácio Lula da Silva (2003-2010) encaminhou ao Congresso Nacional, em dezembro de 2010, proposta de novo Plano Nacional de Educação.

Após amplo processo de discussão, embates, confronto de ideias, que envolveu, em conjunto, a participação da sociedade política e de organismos representativos da sociedade civil, o Projeto de Lei n. ${ }^{\circ} 8.035 / 2010$ tramitou no Congresso Nacional, e a presidente Dilma Vana Rousseff (2011-2014) sancionou, sem vetos, a Lei n. ${ }^{\circ} 13.005$, de 25 de junho de 2014, que aprovou o Plano Nacional de Educação (PNE) 2014-2024 (BRASIL, 2014).

O PNE, organizado com 20 metas e 253 estratégias, estabelece entre as diretrizes "VI - promoção do princípio da gestão democrática da educação pública". O Art. 9. ${ }^{\circ}$ define que

Os Estados, o Distrito Federal e os Municípios deverão aprovar leis específicas para os seus sistemas de ensino, disciplinando a gestão democrática da educação pública nos respectivos âmbitos de atuação, no prazo de 2 (dois) anos contados da publicação desta Lei, adequando, quando for o caso, a legislação local já adotada com essa finalidade (BRASIL, 2014).

É importante considerar a Meta 19, seguida de oito estratégias, que assinala: "assegurar condições, no prazo de dois anos, para a efetivação da gestão 
democrática da educação, associada a critérios técnicos de mérito e desempenho e à consulta pública à comunidade escolar, no âmbito das escolas públicas, prevendo recursos e apoio técnico da União" (BRASIL, 2014, n.p.).

Como se verifica, a efetivação da gestão democrática da educação limita-se ao setor público, prevendo recursos e apoio técnico da União e, de forma contraditória, associada, inicialmente, a critérios de mérito e desempenho, seguida de consulta pública à comunidade escolar. Nesse sentido, chama-se a atenção para a Estratégia 8, que objetiva “[...] desenvolver programas de formação de diretores e gestores escolares, bem como aplicar prova nacional específica, a fim de subsidiar a definição de critérios objetivos para o provimento dos cargos, cujos resultados possam ser utilizados por adesão" (BRASIL, 2014). Ao especificar uma prova técnica, busca regular, por meio de um mecanismo nacional, aqueles que ocuparão tal função em milhares de escolas brasileiras, como acentua Oliveira (2017).

Essa meta apresenta-se como uma orientação "padrão" e, desse modo, vários estados e municípios, a partir dos seus planos de educação, deverão regulamentar a gestão democrática, por meio de legislação específica, no âmbito dos sistemas de ensino e instituir a prova escrita, entre outros critérios (cursos de gestão, seguida de consulta pública) para seleção de gestores e diretores escolares, como é o caso do estado e de alguns municípios de Mato Grosso do Sul (OLIVEIRA, 2017), ou mesmo a indicação política, observando-se a complexidade da organização federativa brasileira, as relações de poder, as diferenças e especificidades locais.

Em Portugal, após a ditadura de 48 anos, com a Revolução de 25 de abril de 1974, o padrão de gestão democrática ou de tipo colegial participativo é o referencial normativo da Constituição da República Portuguesa de 1976 e da Lei de Bases do Sistema Educativo (LBSE) de 1986 (LIMA, 2013).

A LBSE estabelece no Art. $1 .^{\circ},{ }^{\circ}{ }^{\circ} 2$, que

O sistema educativo é o conjunto de meios pelo qual se concretiza o direito à educação, que se exprime pela garantia de uma permanente acção formativa orientada para favorecer o desenvolvimento global da personalidade, o progresso social e a democratização da sociedade (PORTUGAL, 1976, p. 3067).

Segundo Castro (2016), a mencionada lei introduz ou reforça os princípios da democraticidade, da participação, da autonomia e da descentralização no plano educativo, entendendo que "a gestão democrática veiculada pela LBSE 
é um conceito que está intimamente relacionado com conceitos de autonomia e descentralização" (CASTRO, 2016, p. 181). Em outros termos, a LBSE significa um marco para o desenvolvimento das ideias de participação e descentralização, "na medida em que recusa o modelo burocrático e centralizado de administração na sua forma concentrada" (SOUZA; CASTRO, 2012, p. 1200).

Assim, desde maio de 1974, em termos jurídicos, conforme sintetiza Lima (2013):

[...] a direção das escolas portuguesas passou a ser assumida por órgãos colegiais eleitos democraticamente, alguns casos especificando certas competências próprias do presidente do órgão, o qual foi mudando de designação: "comissão de gestão", entre 27 de maio de 1974 (Decreto-Lei n ${ }^{\circ} 221 / 74$ ) e 21 de dezembro daquele ano (Decreto-Lei no 735-A/74); 'conselho diretivo', a partir de dezembro de 1974, embora com arquitetura formal estabilizada através do Decreto-Lei n ${ }^{\circ} 769-\mathrm{A} / 76$, de 23 de outubro, que vigorou até 1998 [...] (LIMA, 2013, p. 59-60).

Desse modo, um novo modelo de administração e gestão foi definido no Decreto-lei n. ${ }^{\circ} 115-\mathrm{A} / 98$, de 4 de maio, e passou a ser conhecido usualmente como o modelo dos contratos de autonomia (AFONSO, 2010). De acordo com o mencionado decreto-lei (Art. 15), além do conselho pedagógico e do conselho administrativo, são órgãos de administração e gestão a assembleia e o conselho executivo ou diretor (PORTUGAL, 1998).

$\mathrm{Na}$ análise de Lima (2013), nesse modelo de gestão a figura do diretor já estava legalmente instituída, embora em uniformidade com o conselho executivo, para todas as escolas e agrupamentos de escolas, cabendo à escola optar por um ou por outro. Esse marco jurídico já indicava as consequências no futuro e remetia a certas concepções da Nova Gestão Pública e de algumas de suas mais conhecidas apropriações no âmbito da administração escolar como liderança (forte, boa, ativa) oriunda da gestão privada, consideradas de tipo racional, eficaz e eficiente.

O Decreto-lei n. ${ }^{\circ} 75 / 2008$, de 22 de abril, que, conforme o Artigo 1, "aprova o regime de autonomia, administração e gestão dos estabelecimentos públicos da educação pré-escolar e dos ensinos básico e secundário", define os órgãos de direção, administração e gestão dos agrupamentos ${ }^{2}$ de escolas e escolas não

2 O Art. 5. ${ }^{\circ}$ do Decreto-lei n. ${ }^{\circ} 115-\mathrm{A} / 98$, de 4 de maio, define o agrupamento escolar como “uma unidade organizacional, dotada de órgãos próprios de administração e gestão, constituída por 
agrupadas: o conselho geral; o diretor; o conselho pedagógico e o conselho administrativo (PORTUGAL, 2008, p. 3350-3359).

De acordo com o mencionado decreto-lei, o conselho geral elege o diretor (Art. 21..$^{\circ}$ ), após procedimento concursal por quatro anos, e não pode ser reconduzido para um quinto mandato consecutivo (Art. $25^{\circ}$ ). O diretor, por sua vez, é o presidente do conselho pedagógico, cuja composição é estabelecida pelo agrupamento de escolas ou escola não agrupada nos termos do regulamento interno e nomeia os demais (o subdiretor e os adjuntos), entre os docentes de carreira que tenham pelo menos cinco anos de serviço e se encontrem em exercício de funções (Art. 21. ${ }^{\circ},{ }^{\circ}{ }^{\circ}$ ) ), assim como preside o conselho administrativo (Art. 37. ${ }^{\circ}$ ) (PORTUGAL, 2008).

Esse decreto-lei, segundo Lima (2013), consagra a figura do diretor, retornando 34 anos depois do 25 de abril de 1974, a um órgão unipessoal, embora eleito pelo agora designado conselho geral.

O modelo atual de gestão das escolas é justificado, conforme preâmbulo do Decreto-lei n. ${ }^{\circ} 75 / 2008$, no sentido de

[...] reforçar as lideranças das escolas, o que constitui reconhecidamente uma das mais necessárias medidas de reorganização do regime de administração escolar. Sob o regime até agora em vigor, emergiram boas lideranças e até lideranças fortes e existem até alguns casos assinaláveis de dinamismo e continuidade. Contudo, esse enquadramento legal em nada favorecia a emergência e muito menos a disseminação desses casos (PORTUGAL, 2008, p. 2342).

Com isso, o diretor obteve centralidade no âmbito da administração local, enquanto o conselho pedagógico, antes considerado um órgão colegial, configurou-se como órgão de apoio ao diretor, perdendo sua capacidade diretiva. A concentração de poderes do diretor sobre o interior da escola manifesta-se quando ele passa, por exemplo, a nomear e a demitir livremente os detentores de outros cargos; a ser responsabilizado perante as autoridades e o órgão mais alto pelos resultados da sua gestão, principalmente a produção de resultados escolares mensuráveis e comparáveis por meio de modalidades de avaliação externa, estandardizada (LIMA, 2014).

Nas palavras de Afonso (2010),

estabelecimentos de educação pré-escolar e de um ou mais níveis e ciclos de ensino, a partir de um projecto pedagógico comum [...]" (PORTUGAL, 1998). 
Trata-se de uma autoridade cuja legitimidade advém agora da revalorização neoliberal do direito a gerir — direito este, por sua vez, apresentado como altamente convergente com a ideia neoconservadora que vê a gestão como uma espécie de tecnologia moral ao serviço de uma nova ordem social, política e económica (AFONSO, 2010, p. 21, grifos do autor).

A análise desses elementos mostra, portanto, a passagem da liderança colegiada para a administração unipessoal (LIMA, 2013). Embora a colegialidade, conforme o autor, não seja garantia de gestão democrática, é a modalidade mais próxima de concepções democráticas de caráter participativo, um elemento teoricamente superior à liderança unipessoal, monocrática não letiva, eventualmente autocrática. A participação no exercício da gestão democrática é insubstituível, como esclarece o autor,

O poder de decidir, participando democraticamente e com os outros nos respectivos processos de tomada das decisões representa o âmago da democracia e, consequentemente, sem participação na decisão não é possível conceber uma gestão democrática das escolas na perspectiva do seu autogoverno. É mesmo essa dimensão político-participativa decisória que confere sentido e substância às anteriores dimensões de eleição e de colegialidade democráticas (LIMA, 2014, p. 1072-1073).

A presença do diretor como a autoridade efetiva emerge, portanto, em um contexto econômico e político predominantemente neoliberal, conforme aqui exposto, sendo que esses elementos (concentração de poderes, livre nomeação e demissão de gestores intermediários, manutenção no poder por um tempo ampliado, responsabilidade pelos resultados da gestão), principalmente por meio de avaliação externa e de prestação de contas (accountability), combinam com os postulados da Nova Gestão Pública, cuja lógica é a de que, sendo adequado para a empresa é, também, para toda a administração pública, e das orientações gerencialistas de tipo empresarial, pautadas nos modelos de governação e em técnicas de gestão que garantam o alcance dos mais elevados padrões de eficácia e eficiência, de competitividade e atratividade, de inovação e diferenciação das escolas (LIMA, 2013).

De todo modo, apesar de o diretor centralizar as decisões, "o processo é comandado pelo poder central que continua a regular, fortemente, os órgãos e instrumentos de gestão educativa ao nível local" e, desse modo, pode-se afirmar 
que quem dirige, em última instância, é o Ministério da Educação (SOUZA; CASTRO, 2012, p. 1207).

As mudanças no modelo de gestão das escolas portuguesas identificam-se com uma representação teórica mecanicista e burocrática, focalizada nos meios e em busca da solução ótima (eficácia), que resulta numa burocracia escolar radicalizada, ampliada, o que Lima (2013) denomina de hiperburocratização, em detrimento da autonomia pedagógica.

Nesse processo, não só no Brasil como em outros países, a Nova Gestão Pública vai sendo assimilada pelos gestores da educação pública, em busca de um Estado supostamente eficiente e dinâmico, com ênfase em mais resultados com menos emprego de recursos. No contexto escolar, "essas orientações vão sendo assumidas como estratégias objetivas e pragmáticas que se apresentam não como forma de responder aos problemas, mas como a única resposta possível" (OLIVEIRA, 2017, p. 725).

Desse modo, os elementos associados à Nova Gestão Pública ganham espaço na educação, com base na ideia de que o privado é o padrão referencial de qualidade para a escola, sendo que pesquisadores como Oliveira $(2015,2017)$, Silva e Duarte (2017), Scaff, Souza e Paxe (2018), Verger, Curran e Parcerisa (2015), entre outros, já avançaram nesse debate ${ }^{3}$, mostrando as implicações desses elementos para as políticas e gestão educacional.

\section{Considerações finais}

A discussão apresentada neste artigo mostra que apesar de o capitalismo continuar dominando como antes e com necessidade de garantir as suas condições de existência, o lugar e a força dos Estados nacionais, mesmo que amplamente alterados, continuam a ser um agente importante no cenário das políticas educacionais.

No contexto de aceleração da globalização econômica, a agenda neoliberal tem orientado as políticas educacionais e as reformas gerencialistas da educação pública têm produzido impactos variados e apropriações diversas nos diferentes

3 Ver o dossiê intitulado "A Nova Gestão Pública no contexto escolar: internacionalização de uma agenda para a educação do século XXI”, organizado por Dalila Andrade de Oliveira e publicado na Revista de Política e Administração da Educação, v. 33, n. 3, em 2017. Ver, também, o dossiê "Políticas de Administração e Gestão em Países da Lusofonia", organizado por Almerindo Janela Afonso e Geovana Mendonça Lunardi Mendes e publicado nos Arquivos Analíticos de Políticas Educacionais, v. 26, n. 129, 2018. 
países e, em decorrência, provocado mudanças nos normativos legais, tanto no Brasil como em Portugal, no que se refere à gestão escolar.

Nesse sentido, cabe ao Estado a função de regular a ação educativa, por meio de novos processos de accountability e de avaliação externa, via testes estandardizados ou mediante cumprimento de metas e responsabilização pelos resultados, coincidentes com a lógica da Nova Gestão Pública, assentada nos critérios de eficiência e de eficácia, da gestão privada de tipo empresarial.

A análise da legislação educacional mostra, no caso do Brasil, que embora a gestão democrática da educação esteja definida na Constituição Federal de 1988 como um dos princípios da educação, reafirmado na LDBEN de 1966, e, portanto, voltada para um processo de decisão baseado na participação e na deliberação pública (CURY, 2002), contraditoriamente, a Meta 19 do PNE 2014-2024, aprovada pela Lei n. ${ }^{\circ} 14.005$, de 2014, associa essa gestão a critérios técnicos de mérito e de desempenho, pautados na visão gerencial, que, em nome de maior eficiência na gestão, toma como indicador de desempenho, em primeira instância, os resultados da avaliação, especialmente de uma prova escrita.

Com isso, em que pese os mecanismos historicamente construídos na educação brasileira, a gestão democrática da educação ainda tem um longo percurso no âmbito de um projeto de escola pública de qualidade que se quer no país, articulado com a construção do Sistema Nacional de Educação (SAVIANI, 2014). E, nesse sentido, "Os cidadãos querem mais do que serem executores de políticas, querem ser ouvidos e ter presença em arenas públicas de elaboração e nos momentos de tomada de decisão. Trata-se de democratizar a própria democracia" (CURY, 2002, p. 172, grifos do autor), por exemplo, como os múltiplos conselhos hoje existentes com funções de controle e fiscalização da educação obrigatória, da merenda, dos recursos financeiros, entre outros, e os orçamentos participativos em diversos municípios do país (CURY, 2002).

Em Portugal, embora a Constituição de 1976 da República Portuguesa e a experiência no país ao longo de três décadas quanto aos órgãos de governo escolar tenham sido decisivas para a associação entre democracia e colegialidade (LIMA, 2014), verifica-se que o Decreto-lei n. ${ }^{\circ} 75 / 2008$, de 22 de abril, diminui o poder de decisão colegiada e confirma a gestão unipessoal, centrada no diretor escolar e, nesse sentido, despolitiza a participação, elemento essencial da gestão democrática.

Ainda, apesar de o discurso da autonomia das escolas, conceito relacionado à gestão democrática, estar presente nos normativos legais, também associado à ideia de que cada escola deve construir o seu projeto educativo (COSTA, 2003), constata-se o recuo na autonomia das organizações e dos atores escolares portugueses (AFONSO, 2010).

Feitas essas considerações, pode-se afirmar que no contexto de extensão e influência da ordenação neoliberal, em decorrência da redefinição do papel 
do Estado e, especialmente, das orientações advindas dos postulados da Nova Gestão Pública nas políticas educacionais, utilizando os termos de Lima (2013), há uma ruptura no princípio da gestão democrática, embora com especificidades próprias de cada contexto nacional, com a ascensão de um modelo de gestão das escolas, centrado na eficácia e na eficiência, em ambos os países.

Do exposto, entende-se que a participação colegiada nas decisões, uma dimensão essencial da gestão democrática, de modo a criar espaços e tempos organizacionais coletivos, de diálogo e deliberação nas escolas, não pode deixar de ser reivindicada, debatida e analisada, por exemplo, por meio de estudos empíricos, associada a um projeto político de sociedade democrática, capaz de fazer frente à lógica gerencial que vem se afirmando e promovendo contradições, disputas e desafios de construção de novas relações e mecanismos democráticos na educação.

\section{REFERÊNCIAS}

ADRIÃO, T. Educação e produtividade: a reforma do ensino paulista e a desobrigação do Estado. São Paulo: Xamã, 2006.

ADRIÃO, T.; BEZERRA, E. O setor não lucrativo na gestão da educação pública: corresponsabilidade ou debilidade. Currículo sem Fronteiras, v. 13, n. 2, p. 256-268, maio/ago. 2013.

AFONSO, A. J. Políticas educativas e avaliação educacional: para uma análise sociológica da reforma educativa em Portugal (1985-1995). Centro de Estudos em Educação e Psicologia, Instituto de Educação e Psicologia. Universidade do Minho, 1998.

AFONSO, A. J. A redefinição do papel do Estado e as políticas educativas: elementos para pensar a transição. Sociologia, Problemas e Práticas, n. 37, p. 33-48, 2001.

AFONSO, A. J. Gestão, autonomia e accountability na escola pública portuguesa: breve diacronia. Revista Brasileira de Política e Administração da Educação, v. 26, n. 1, p. 13-30, jan./abr. 2010.

AFONSO, A. J. Para uma concetualização alternativa de accountability em educação. Educação e Sociedade, Campinas, v. 33, n. 119, p. 471-484, abr.jun. 2012.

ANTUNES, R. Os sentidos do trabalho: ensaios sobre a afirmação e a negação do trabalho. São Paulo: Boitempo, 1999. 
ANTUNES, F. Reforma do Estado e políticas públicas: a governação em ação. Notas de um estudo no campo da Educação e Formação de Adultos em Portugal. In: PERONI, V. M. V. (Org.). Redefinições das fronteiras entre o público e o privado: implicações para a democratização da educação. Brasília: Líber Livro, 2013. p. 82-119.

BRASIL. Constituição da República Federativa do Brasil. Brasília 5 out. 1988. Diário Oficial da União. Brasília, 1998. Disponível em: < http://www.planalto.gov.br/ccivil_03/ constituicao/constituicaocompilado.htm>. Acesso em: 20 abr. 2012.

BRASIL. Emenda Constitucional no. 19, de 4 de junho de 1998. Modifica o regime e dispõe sobre princípios e normas da Administração Pública, servidores e agentes políticos, controle de despesas e finanças públicas e custeio de atividades a cargo do Distrito Federal, e dá outras providências. Brasília, 1998. Disponível em: $<$ http://www.planalto. gov.br/ccivil_03/constituicao/emendas/emc/emc19.htm>. Acesso em: 10 maio 2015.

BRASIL. Lei $n^{\circ}$ 9.394, de 20 de dezembro de 1996. Aprova as Diretrizes e Bases da Educação Nacional. Brasília. Disponível em: <https://www.planalto.gov.br/ccivil_03/ Leis/L9394.htm>. Acesso em: 12 dez. 2013.

BRASIL. Lei 10.172, de 9 de janeiro de 2001. Aprova o Plano Nacional de Educação e dá outras providências. Brasília, 2001. Disponível em: $<$ http://portal.mec.gov.br/arquivos/ pdf/L10172.pdf>. Acesso em: 10 maio 2015.

BRASIL. Lei $n^{\circ} 13.005$, de 25 de junho de 2014. Aprova o Plano Nacional de Educação e dá outras providências. Brasília, 2014. Disponível em: <https://www.planalto.gov.br/ ccivil_03/_ato2011-2014/2014/lei/113005.htm>. Acesso em: 10 maio 2015.

BRASIL. Plano Diretor da Reforma do Aparelho do Estado. Brasília: MARE, 1995.

CASTRO, D. Reconfiguração do discurso político-normativo: da lógica democrática à lógica gerencialista. Revista Exitus, Santarém, PA, v. 6, n.2, p. 180-193, jul./dez. 2016.

COSTA, J. A. Projectos educativos das escolas: um contributo para a sua (des)construção. Educação e Sociedade, Campinas, v. 24, n. 85, p. 1319-1340, dez. 2003.

CURY, C. R. J. Gestão democrática da educação: exigências e desafios. Revista Brasileira de Política e Administração da Educação. Porto Alegre: ANPAE, v. 18, n. 2, jul./ dez., p. 163-174, 2002.

CURY, C. R. J. Sentidos da educação na Constituição Federal de 1988. Revista Brasileira de Política e Administração da Educação, Recife: ANPAE, v. 29, n. 2, p. 195-206, maio/ago. 2013.

DALE, R. A sociologia da educação e o Estado após a globalização. Educação e Sociedade, Campinas, v. 31, n. 113, p. 1099-1120, out.-dez. 2010.

DALE, R.; GANDIM, L. A. Estado, globalização, justiça social e educação: reflexões contemporâneas de Roger Dale. Currículo sem Fronteiras, v. 14, n. 2, p. 5-16, maio/ago. 2014.

FERNANDES, M. D. E.; SCAFF, E. A. S.; OLIVEIRA, R. T. C. Direito à educação e compromisso docente: quando o sucesso e o fracasso escolar encontram o culpado. 
Revista Brasileira de Política e Administração da Educação, Porto Alegre, v. 29, n. 2, p. 327-345, maio/ago. 2013.

FRIGOTTO G. Os circuitos da história e o balanço da educação no Brasil na primeira década do século XXI. Revista Brasileira de Educação, Rio de Janeiro: ANPEd, v. 16, n. 46 , p. 235-254, jan./abr. 2011.

HARVEY, D. Condição pós-moderna: uma pesquisa sobre as origens da mudança cultural. São Paulo: Edições Loyola, 2013.

HARVEY, D. O neoliberalismo: história e implicações. São Paulo: Loyola, 2012.

HOBSBAWM, E. Era dos extremos: o breve século XX: 1914-1991. São Paulo: Companhia das Letras, 2008.

LIMA, L. C. Diretor(a) de escola pública: unipessoalidade e concentração do poder no quadro de uma relação subordinada. In: PERONI, V. M. V. (Org.). Redefinições das fronteiras entre o público e o privado: implicações para a democratização da educação. Brasília: Líber Livro, 2013. p. 58-81.

LIMA, L. C. Gestão democrática das escolas: do autogoverno à ascensão de uma pós-democracia gestionária? Educação e Sociedade, Campinas, v. 35, n. 129, p. 1067-1083, out./dez. 2014.

LIMA, L. C. Modernização, racionalização e optimização: perspectivas neotaylorianas na organização e administração da educação. In: LIMA, L. C.; AFONSO, A. J. Reformas da educação pública: democratização, modernização, neoliberalismo. Porto: Edições Afrontamento, 2002. p. 17-32.

MÉSZÁROS, I. A crise estrutural do capital. São Paulo: Boitempo, 2009.

NETTO, J. P. FHC e a política social. In: LESBAUPIN, I. (Org.). O desmonte da nação: Balanço do Governo FHC. Petrópolis: Vozes, 1999.

OLIVEIRA, D. A. Nova gestão pública e governos democráticos-populares: contradições entre a busca da eficiência e a ampliação do direito à educação. Educação e Sociedade, Campinas, v. 36, n. 132, p. 625-646, jul./set. 2015.

OLIVEIRA, D. A.; DUARTE, A. W. B.; CLEMENTINO, A. M. A Nova Gestão Pública no contexto escolar e os dilemas dos(as) diretores(as). Revista Brasileira de Política e Administração da Educação, Goiânia: ANPAE, v. 33, n. 3, p. 707-728, set./dez. 2017.

OLIVEIRA, R.T.C. Do Plano Nacional de Educação (2014-2024) ao Plano Estadual de Educação de Mato Grosso do Sul (2014-2024): a gestão democrática em questão. Série-Estudos, Campo Grande, MS, v. 22, n. 44, p. 221-238, jan./abr. 2017.

PARO, V. H. Crítica da estrutura da escola. São Paulo: Cortez, 2011.

PERONI, V. M. V. A gestão democrática da educação em tempos de parceria entre o público e o privado. Pro-Posições: Revista Quadrimestral da Faculdade de Educação Unicamp. Campinas-SP, v. 23, n. 2(68), p. 19-31, maio/ago. 2012. 
PERONI, V. M. V. A privatização do público: implicações para a democratização da educação. In: PERONI, V. M. V. (Org. ). Redefinições das fronteiras entre o público e o privado: implicações para a democratização da educação. Brasília: Líber Livro, 2013. p. 9-32.

PERONI, V. M. V.; OLIVEIRA, R. T. C.; FERNANDES, M. D. E. Estado e terceiro setor: as novas regulações entre o público e o privado na gestão da educação básica brasileira. Educação \& Sociedade, Campinas, v. 30, n. 108, p. 761-778, out. 2009.

PORTUGAL. Constituição da República Portuguesa de 1976. Diário da República, Lisboa, 2 de abr. 1976.

PORTUGAL. Decreto-Lei n 115-A/98, de 4 de maio de 1998. Diário da República, n. 102, I Série A, 1998.

PORTUGAL. Decreto-Lei n. 75/2008, de 22 de abril de 2008. Regime de autonomia, administração e gestão dos estabelecimentos públicos da educação pré-escolar e dos ensinos básico e secundário. Diário da República, 2008.

PORTUGAL. Lei n. 46, de 14 de outubro de 1986. Lei de Bases do Sistema Educativo Português. Diário da República, Lisboa, n. 237, Série I, 14 out. 1986.

SAVIANI, D. A educação na Constituição Federal de 1988: avanços no texto e sua neutralização no contexto dos 25 anos de vigência. Revista Brasileira de Política e Administração da Educação, Recife: ANPAE, v. 29, n. 2, p. 207-221, maio/ago. 2013.

SAVIANI, D. Sistema Nacional de Educação e Plano Nacional de Educação: significado, controvérsias e perspectivas. Campinas, SP: Autores Associados, 2014.

SCAFF, E. A. S.; SOUZA, K. R.; PAXE, I. Implicações da Nova Gestão Pública para a educação: análise comparativa entre Brasil e Angola. Arquivos Analíticos de Políticas Educacionais, Arizona State University, v. 26, n. 131, p. 1-29, 2018.

SILVA, L. F.; DUARTE, A. Gestão por resultados e a participação da comunidade escolar. Revista Brasileira de Política e Administração da Educação, Goiânia: ANPAE, v. 33, n. 3, p. 751-769, set./dez. 2017.

SOUZA, D.; CASTRO, D. Gestão democrática da educação sob perspectiva comparada Brasil-Portugal: entre a exigência legal e a exequibilidade real. Educação \& Sociedade, Campinas: CEDES, v. 33, n. 121, p. 1195-1213, 2012.

VERGER, A.; CURRAN, M.; PARCERISA, L. La trayectoria de una reforma educativa global: el caso de la nueva gestión pública en el sistema educativo catalán. Educação \& Sociedade, Campinas, v. 36, n. 132, p. 675-697, jul./set. 2015.

Texto recebido em 29 de outubro de 2018.

Texto aprovado em 23 de janeiro de 2019. 